IJPSR (2010), Vol. 1, Issue 11

(Research Article)

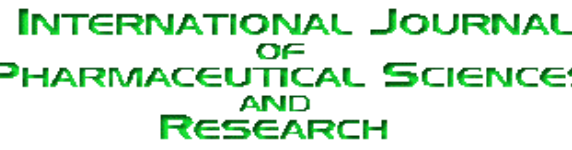

Received on 22 August, 2010; received in revised form 17 October, 2010; accepted 26 October, 2010

\title{
VALIDATED HPTLC METHOD FOR SIMULTANEOUS DETERMINATION OF LAMIVUDINE AND ABACAVIR SULPHATE IN TABLET DOSAGE FORM
}

T. Sudha* ${ }^{1}$, V. R. Ravikumar ${ }^{2}$ and P. V. Hemalatha ${ }^{2}$

Department of Pharmaceutical Analysis ${ }^{1}$, Department of Pharmacognosy ${ }^{2}$, The Erode College of Pharmacy\& Research Institute, Erode, Tamil Nadu, India

Keywords:

Abacavir sulphate, Lamivudine,

Simultaneous Estimation, HPTLC,

Validation

Correspondence to Author:

T. Sudha

Department of Pharmaceutical Analysis, The Erode College of Pharmacy\& Research Institute, Erode, Tamil Nadu, India

\section{ABSTRACT}

A simple, precise, accurate and rapid high performance thin layer chromatographic method has been developed and validated for the simultaneous estimation of Lamivudine and Abacavir sulphate in combined dosage forms. The stationary phase was precoated silica gel $60_{\mathrm{F}} 254$. The mobile phase used was a mixture of (Acetone: chloroform: methanol 4: 4: $2 \mathrm{v} / \mathrm{v} / \mathrm{v}$ ). The detection of spot was carried out at $265 \mathrm{~nm}$. The method was validated in terms of linearity, accuracy, precision and specificity. The calibration curve was found to be linear between 500 to 3000 ng with regression coefficient of 0.9998 . The proposed method can be successfully used to determine the drug content of marketed formulation. 
INTRODUCTION: The combination of Lamivudine (LAM) and Abacavir (ABA) has recently been introduced in the market. Chemically Lamivudine 1 is (Lam) 4 amino-1- [2R, 5S) - 2- (hydroxyl methyl) - 1, 3- oxathiolan- 5yl] pyrimidine-2-one. Lamivudine is a nucleoside reverse transcriptase inhibitor (NRTI) with an activity against human immunodeficiency virus type (1) (HIV) 1 and hepatitis B. Abacavir ${ }^{2}$ is (Aba) [1R] - 4- (2 amino6-cyclopyridine) purine- 9- yl) -1- cyclopent- 2 enyl] methanol. It is a nucleoside reverse transcriptase inhibitor (NRTI) with an activity against human immune deficiency virus Type (1) (HIV1).

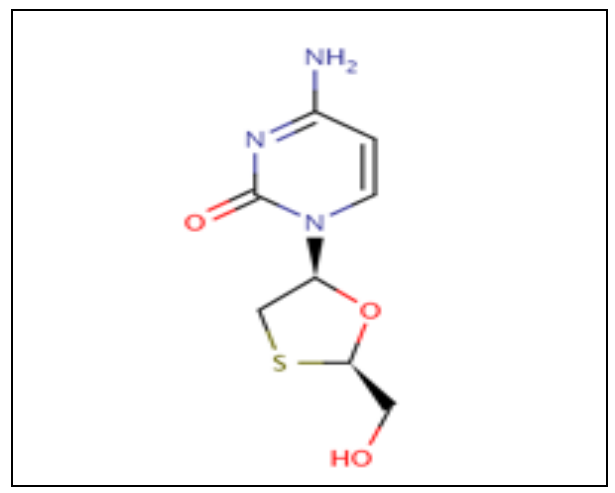

LAMIVUDINE

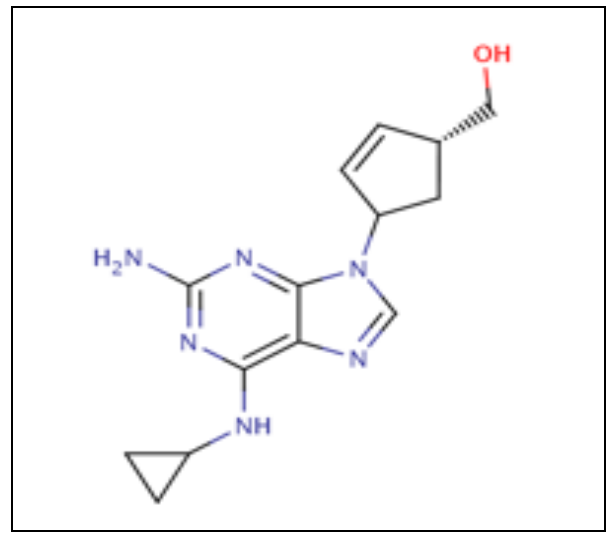

ABACAVIR SULPHATE

The drugs are prescribed invidually, as well as multicomponent dosage forms available in the market. A number of methods have been published for the estimation of above said analytes.

- Spectrophotometric estimation of Abacavir sulphate ${ }^{3}$

- Spectrophotometric estimation of Lamivudine 4

- Lamivudine in human plasma by RP-HPLC ${ }^{5}$

- Titrimetric and spectrophotometric estimation of Lamivudine ${ }^{6}$

A method was reported for simultaneous analysis of Abacavir and Lamivudine in human plasma by LC/MS/MS ${ }^{7}$. Determination of Abacavir, Lamivudine, Zidovudine in pharmaceutical tablets human serum and in drug dissolution studies by HPLC ${ }^{8}$ was also reported in the literature. Literature survey reveals that so, far no HPTLC method has been reported for the simultaneous estimation of $A B A$ and Lam formulation. In the present HPTLC studies investigation, an attempt have been made to develop a rapid, accurate, precise and cost effective HPTLC method for simultaneous estimation of LAM and $A B A$ in combined dosage form.

MATERIALS AND METHODS: LAM and ABA standards were procured as a gift samples from Hetero labs Hyderabad. Silica gel 60 254 TLC plates $(4 \times 10 \mathrm{~cm})$ were used as stationary phase. All chemicals and reagents used were of analytical grade and obtained from Qualigens. Marketed formulation Abamune-L, manufactured by containing Aba (600mg) and Lam (300mg) was used for the analysis. The instrument used in the present study was Camag Linnomat V- automatic sample applicator, Hamilton syringe $(100 \mu \mathrm{l})$ camag TLC scanner 3, cagmag Wincats soft ware, cagmag Twin through chamber $(4 \times 10 \mathrm{~cm})$. To carry out HPTLC analysis ${ }^{9}$ the TLC plates were prewashed with methanol. Activation of plates was done in an oven at $50^{\circ} \mathrm{C}$ for 5 minutes. The chromatographic conditions maintained were 
precoated silica gel $60_{\mathrm{F}} 254$ aluminum sheets $(4 \times 10 \mathrm{~cm})$ as stationary phase, Acetone: chloroform: methanol (4: 4: $2 \mathrm{v} / \mathrm{v} / \mathrm{v}$ ) as mobile phase, chamber and plate saturation time of 30 min, migration distance was $90 \mathrm{~mm}$, wavelength was selected by scanning standard solution of both drugs over $200 \mathrm{~nm}$ to $400 \mathrm{~nm}$. LAM showed maximum absorbance at $366 \mathrm{~nm}$ and $\mathrm{ABA}$ at 254 $\mathrm{nm}$. Both components showed reasonably good response at $265 \mathrm{~nm}$. Therefore photometric measurements were performed at $265 \mathrm{~nm}$ absorption mode with cagmag TLC scanner 3 using win CATS soft ware. Stock solutions of LAM and $A B A$ were prepared by separately dissolving $25 \mathrm{mg}$ of Aba and $25 \mathrm{mg}$ of Lam in $25 \mathrm{ml}$ methanol. Further dilution was made by diluting $2.5 \mathrm{ml}$ with mobile phase to obtain $50 \mu \mathrm{g} / \mathrm{ml}$ solutions. Working stock solution were prepared by diluting the stock solution with mobile phase to obtain final concentration of $5,10,15,20,25$ and $30 \mu \mathrm{g} / \mathrm{ml}$ of both drugs (LAM and ABA ) were applied separately on the TLC plate.

TLC plate was dried, developed and analyzed photometrically as described earlier. The calibration graph was plotted using peak area against concentration. The procedure was repeated for three times to determine the LOD and LOQ. The marketed formulation Abamune-L contains (300mg of LAM and $600 \mathrm{mg}$ of ABA). Twenty tablets were weighed accurately, finely powered and mixed. The average mass per tablet was determined. The powder tablet equivalents to $25 \mathrm{mg}$ of each were accurately weighed and added a minimum quantity of methanol to dissolve the substance the total volume as brought to $25 \mathrm{ml}$ with more methanol (1000 $\mu \mathrm{g} / \mathrm{ml}$ ) in a volumetric flask. The solutions were sonicated for 10 minutes and then filtered through whatmann filter paper No 41 to separate out the insoluble excipients. Collect the filtrate after rejecting the first portion of the filtrate.
From the clear solution, further dilutions were made by diluting $2.5 \mathrm{ml}$ to $50 \mathrm{ml}$ with mobile phase to obtain $50 \mu \mathrm{g} / \mathrm{ml}$ further dilution was made by diluting $3 \mathrm{ml}$ to $10 \mathrm{ml}$ with mobile phase to obtain $15 \mu \mathrm{g} / \mathrm{ml}$. 15 micro liters of sample solutions were spotted on to the TLC plate and developed. The analysis was repeated for six times. The content of the drug was calculated from the peak areas recorded. The accuracy of the method was confirmed by recovery studies. The recovery was performed at three different concentrations $(20 \%, 40 \%, 60 \%)$ were added to fixed amount of pre analyzed sample and the amount of each of the drug were determined by the proposed method. Further the precision of the developed method was confirmed by interday and intraday analysis.

RESULTS AND DISCUSSION: A simple, precise, accurate HPTLC method has been developed for the estimation of Lamivudine and Abacavir sulphate in bulk and in tablet formulation. A cagmag HPTLC instrument was used for the analysis. The mobile phase containing acetone: chloroform: methanol $(4: 4: 2 \mathrm{v} / \mathrm{v} / \mathrm{v})$. Rf values of 0.09 and 0.34 for $L A M$ and $A B A$ respectively with dense and compact spots desired for quantification of Aba and Lam in pharmaceutical formulations (fig-1). The linearity of an analytical method to its ability to elicit test results that are directly or by a well defined mathematical transformation proportional to the concentration of analyte samples with in a given range. The linearity of the method was observed with in the expected range demonstration its suitability for analysis. The linearity concentrations range of 5 to $30 \mu \mathrm{g} / \mathrm{ml}$. The correlation coefficient $r^{2}$ value $(n=3)$ for LAM and ABA were found to be 0.9996 and 0.9998 respectively. The value of intercept was less than $2 \%$ of the response of $100 \%$ of the test concentration in all cases indicates functional linear relationship between the concentration of 
analyte and area under the peak area. The proposed method was validated as per $\mathrm{ICH}$ guidelines ${ }^{10,11}$.

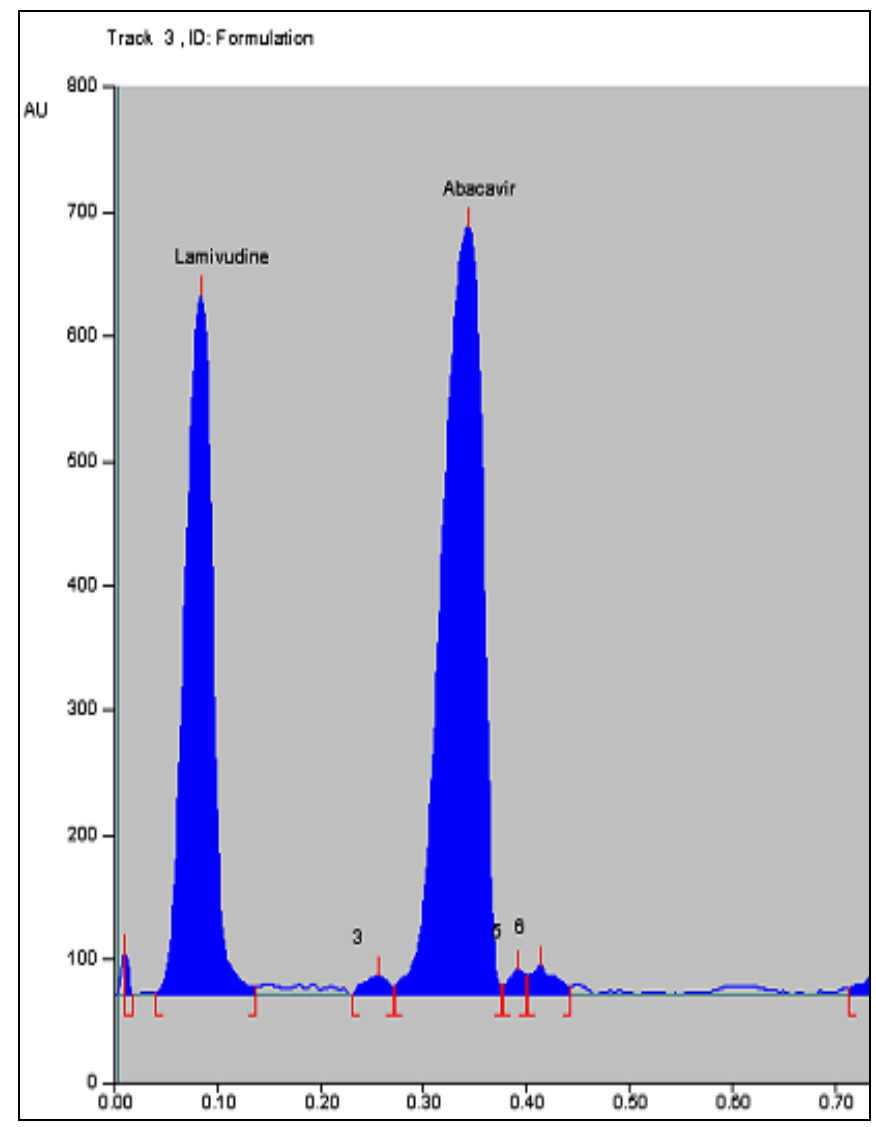

FIG.1: A TYPICAL HPTLC CHROMATOGRAM OF LAM AND ABA

Limit of Quantification was found to be 0.0254 and $0.0105 \mu \mathrm{g} / \mathrm{ml}$ for LAM and ABA respectively. Limit of detection was found to be 0.0083 and $0.0034 \mu \mathrm{g} / \mathrm{ml}$ for LAM and ABA respectively (Table 1). Precision is the degree of reproducibility or repeatability of the method under normal operating condition. The method passed the test for repeatability as determined by $\%$ RSD ${ }^{12}$ of the peak area of six replicate. The $\%$ concentration of LAM and ABA were found to be $100.01 \pm 0.4300$ and $99.50 \pm 0.5911$ respectively.
TABLE-1: METHOD VALIDATION PARAMETERS

\begin{tabular}{|c|c|c|}
\hline \multirow{2}{*}{ Parameters } & \multicolumn{2}{|c|}{ Values } \\
\hline & Lamivudine & Abacavir \\
\hline Linearity range & $5-30 \mu \mathrm{g} / \mathrm{ml}$ & $5-30 \mu \mathrm{g} / \mathrm{ml}$ \\
\hline $\begin{array}{l}\text { Correlation } \\
\text { coefficient }\end{array}$ & 0.9996 & 0.9998 \\
\hline $\begin{array}{l}\text { Regression } \\
\text { equation }\end{array}$ & $Y=1993.37 X+571.05$ & $Y=3965.88 X+279.30$ \\
\hline Slope & 1993.37 & 3965.88 \\
\hline Intercept & 571.02 & 279.30 \\
\hline $\begin{array}{l}\text { Limit of } \\
\text { detection }\end{array}$ & 0.0083 & 0.0034 \\
\hline $\begin{array}{c}\text { Limit of } \\
\text { Quantification }\end{array}$ & 0.0254 & 0.0105 \\
\hline
\end{tabular}

The low \% RSD value indicated that the method has good precision. The results of the analysis are shown in Table 2. Further the precision of the developed method is confirmed by interday and intraday analysis. The result show good agreement with the label claim of the formulation. To evaluate the accuracy of the method, known amount of pure drug was added to the previously analyzed solution containing pharmaceutical formulation and the mixture was analyzed by the proposed method and the recoveries were calculated.

To evaluate the accuracy of the method, known amount of pure drug was added to the previously analyzed solution containing pharmaceutical formulation and the mixture was analyzed by the proposed method and the recoveries were calculated. The \% recovery of LAM and ABA were found in the range of 100.33 \pm 99.88 and $99.83 \pm 100.41$ respectively. The $\%$ RSD value for LAM and ABA were found to be 0.2269 and 0.3078 respectively. The low percentage RSD value indicated that there is no interference due to the excipients used in formulation. Hence the accuracy of the method was confirmed (Table 3). Specificity is the ability to asses unequivocally the analyte in the presence of components that may be expected to be present in the sample matrix. 
TABLE 2: ASSAY OF LAM AND ABA

\begin{tabular}{|c|c|c|c|c|c|c|c|}
\hline Formulation & Drugs & Label claim & $\begin{array}{l}\text { Amount } \\
\text { found }\end{array}$ & \%purity & Average & SD & \%RSD \\
\hline \multirow{9}{*}{ Abamune-L } & \multirow{4}{*}{ Lamivudine } & \multirow{4}{*}{$300 \mathrm{mg}$} & 298.642 & 99.54 & \multirow{4}{*}{100.01} & \multirow{4}{*}{0.4300} & \multirow{4}{*}{0.4299} \\
\hline & & & 300.114 & 100.03 & & & \\
\hline & & & 299.190 & 99.73 & & & \\
\hline & & & 299.164 & 99.72 & & & \\
\hline & \multirow{5}{*}{ Abacavir } & \multirow{5}{*}{$600 \mathrm{mg}$} & 599.190 & 99.86 & \multirow{5}{*}{99.50} & \multirow{5}{*}{0.5911} & \multirow{5}{*}{0.5940} \\
\hline & & & 603.285 & 100.54 & & & \\
\hline & & & 594.190 & 99.03 & & & \\
\hline & & & 595.266 & 99.21 & & & \\
\hline & & & 596.190 & 99.36 & & & \\
\hline
\end{tabular}

TABLE-3: RECOVERY STUDIES OF LAM AND ABA

\begin{tabular}{ccccc}
\hline Label claim & Amount Added & $\begin{array}{c}\text { Amount } \\
\text { Recovered }\end{array}$ & \% Recovery & Average \\
\hline \multirow{2}{*}{ Lam 300mg } & 3.00 & 3.01 & 100.33 & 0.2272 \\
& 6.00 & 6.01 & 100.16 & 100.12 \\
\hline \multirow{2}{*}{ Aba600mg } & 9.00 & 8.99 & 99.88 & 100.06 \\
& 6.0 & 5.99 & 99.83 & 0.3080 \\
\end{tabular}

CONCULSION: The HPTLC method developed for LAM and ABA shows good precision and accuracy. The low \% RSD value in the recovery studies indicates that there is no excepients used in the formulation. Hence, it is concluded that the developed method is simple, precise, accurate and rapid for the analysis of LAM and ABA in pure and tablet dosage form. Then the developed method can be adopted for the routine analysis of LAM and ABA in bulk and in tablet dosage form.

\section{REFERENCES:}

1. Indian Pharmacopoeia, vol. 2, Govt. of India, Ministry of Health \& Family Welfare, Sector-3, RajNagar, Ghaziabed, 201002, 2007, pp-674.

2. Indian Pharmacopoeia, vol. 2, Govt. of India, Ministry of Health \& Family Welfare, Sector-3,RajNagar, Ghaziabed,201002, 2007, 1276

3. Ramanamurthy, Hiremath S. and Appala Raju N. Spectrophotometric determination of Abacavir sulphate. The Indian pharmacist, 2006, vol. 5, 91-92.

4. Shalini S, Shanooja V. P., Abdul Jameel S, and Basima. Application of UV spectrophotometric method for estimation of Lamivudine in tablets. Digest Journal of Nanomaterials and Biostructure 2009, vol 4:(2) 357-360

5. Kano.E.K, dos Reis serra. C.H, Koono. E. E and Andrade's. Determination of lamivudine in human plasma by HPLC and its use in bioequivalence study.Int.J. Pharm, 2005, 297(1-2), 7379.

6. Basavaiah.K, Somasekar. Titrimetric and Spectrophotometric estimation of Lamivudine. Indian Journal of chemical technology. Vol 13, 2006, 7-11.

7. Noel.A.Gomes, Ashutosh. Simultaneous estimation of Abacavir and Lamivudine in human plasma by LC/MS/MS. Journal pharm biomed anal, 2008, 48(3), 918-26.

8. Savaser.A, and Goraler. S. Determination of Abacavir, Lamivudine and Zidovudine in Pharmaceutical tablets human serum and in drug dissolution studies by HPLC. Chromatagraphia, 2007, vol 65, 5-6.

9. Sethi P. D. HPTLC Quantitative Analysis of Pharmaceutical formulations, I $^{\text {st }}$ ed, New Delhi, CBS, Publishers; 2001.

10. International conference on Harmonization guidance for Industry In: Q2A Text on validation of Analytical methods. Switzerland, IFPMIA: 1994, 1, 4.

11. International conference on Harmonization guidance for Industry In: Q2B Text on validation of Analytical methods. Zwiterland, IFPMIA: 1996, 1-8.

12. Gupta. S. C. and Kapoor. V. K. Fundamentals of mathematical statistics. $9^{\text {th }}$ edition. Sultan chand and sons. New Delhi, 1994, 2.6, 3.2-3.8 